\title{
Editorial
}

\section{EJPSR - Additional Milestones Accomplished}

\author{
Martin Lacher ${ }^{1}$ \\ ${ }^{1}$ Klinik und Poliklinik für Kinderchirurgie, Universitätsklinikum Leipzig, \\ Leipzig, Germany \\ Eur J Pediatr Surg Rep 2015;3:59-60.
}

The European Journal of Pediatric Surgery Reports (EJPS Reports) is releasing its 4th issue, the second of 2015.

In the past months EJPS Reports has reached two important milestones as it builds a reputation for publishing highquality pediatric surgical case reports.

In addition to being freely and immediately available online, all articles published in the journal are now searchable in PubMed thanks to the journal indexing in PubMed Central, resulting in published cases being much more prominent, integrated, and accessible.

The second important landmark is the linking of EJPS Reports to the European Pediatric Surgeon's Association (EUPSA), reflecting the relationship to the mother journal European Journal of Pediatric Surgery (EJPS). EJPS Reports has recently become an official EUPSA publication organ for case reports. In the future, this nomination will give us the privilege to hold a dedicated case report session with at least the 10 best rated posters at the Annual EUPSA meeting. A selection of those articles will be published in a congress issue with the best three cases being rewarded with a prize.

As the editor of this journal I strongly believe that properly described case reports can make a valuable contribution to surgical research and education. The nature of open-access with no paywalls for readers online, allows us to see, almost in real-time, what articles are of interest to readers of the journal. This is highlighted by a report in the last issue (EJPS Reports, 2015; 3(1): 3-6) on how the histology of the appendix can mislead the surgeon in total colonic Hirschsprung disease. This article very quickly became this year's most downloaded article and was awarded with the annual prize for the "best case report of the year" as a reflection of this success.

This fourth issue of EJPS Reports consists of 11 case reports representing a wide range of pediatric surgical disciplines, including new surgical techniques and novel operative approaches. We again selected articles on surgical complications because those are often more challenging and of higher educative value to the reader than reports on perfect results. If our readers face a difficult case they should ask this question: "Is there anything I have learnt from this case that might help my fellow clinicians?" If the answer is yes and they have illustrative radiological studies or clinical images they might well have the seeds of an interesting case report and the chance to make a difference by adding to our knowledge base and improving pediatric surgical care.

The EJPS Reports is a journal that has been created to provide a platform to share the best case reports in pediatric surgery and we invite you to submit your best and most interesting cases. We look forward to your contribution.

\footnotetext{
Address for correspondence

DOI http://dx.doi.org/

Martin Lacher, MD, PhD, Klinik

10.1055/s-0035-1570036. und Poliklinik für Kinderchirurgie, ISSN 2194-7619.

Universitätsklinikum Leipzig,

Liebigstraße 20A, 04103 Leipzig,

Germany (e-mail: Martin.

Lacher@medizin.uni-leipzig.de).
}

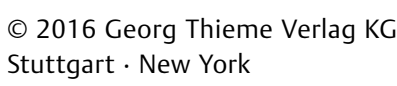

\section{License terms

